\title{
Unexpected Association of HIV, Hepatitis C Virus Infection, Lymph Node Tuberculosis, and Sickle Cell Disease: A Case Report in a 35-Year-0ld Woman from Cameroon
}

\author{
Hilaire Djantio ${ }^{*}$, Gilder Tonfack Temgoua², Vassili Aurel Njami ${ }^{3}$, Serge Lombat ${ }^{4}$, \\ Rahim Seid Ndam', Louisiane Ngong Mbella1, Bertrand Hugo Mbatchou Ngahane ${ }^{5,6}$ \\ ${ }^{1}$ International Centre of Medical Imaging and Medicine, General Medicine, Douala, Cameroon \\ ${ }^{2}$ Deido District Hospital, Infectiology Department, Douala, Cameroon \\ ${ }^{3}$ Mbanga District Hospital, General Medicine, Douala, Cameroon \\ ${ }^{4}$ International Centre of Medical Imaging and Medicine, Radiology Department, Douala, Cameroon \\ ${ }^{5}$ Douala General Hospital, Internal medicine/Pneumology, Douala, Cameroon \\ ${ }^{6}$ Faculty of Medicine and Pharmaceutical Science, University of Douala, Douala, Cameroon \\ Email: ^djantiohilaire@gmail.com
}

How to cite this paper: Djantio, H., Temgoua, G.T., Njami, V.A., Lombat, S., Ndam, R.S., Mbella, L.N. and Ngahane, B.H.M. (2019) Unexpected Association of HIV, Hepatitis C Virus Infection, Lymph Node Tuberculosis, and Sickle Cell Disease: A Case Report in a 35-Year-Old Woman from Cameroon. Open Journal of Immunology, 9, 21-27.

https://doi.org/10.4236/oji.2019.92002

Received: May 21, 2019

Accepted: June 27, 2019

Published: June 30, 2019

Copyright $\odot 2019$ by author(s) and Scientific Research Publishing Inc. This work is licensed under the Creative Commons Attribution International License (CC BY 4.0).

http://creativecommons.org/licenses/by/4.0/

\begin{abstract}
Introduction: HIV infection is a public health issue. Developing countries are facing the challenge of patient populations that remain undiagnosed and under-served in combined antiretroviral treatment (cART) leading to opportunistic infections. Lymph node tuberculosis is one of the most common. His firm diagnosis is not always easy in resources limited country. Case Presentation: We report a case of a 35-year-old woman known HIV for the past 10 years but not on treatment. She presented with a four-month history of fatigue, weight loss and pain in the right flank. The diagnosis of lymph node tuberculosis, hepatitis c virus infection and sickle cell disease was done. After 6 months of treatment, there was a favourable clinical evolution. Conclusion: This case report highlights the necessity to screen for opportunistic and non-opportunistic co-infection in HIV infected patient.
\end{abstract}

\section{Keywords}

HIV, Hepatitis C, Tuberculosis, Sickle Cell Disease

\section{Introduction}

In 2016 an estimated 36.7 million people were living with HIV worldwide [1]. Despite the fact that sub-Saharan Africa contains only about 12 percent of the 
Earth's population, the region is the world's epicentre of human immunodeficiency virus (HIV)/acquired immunodeficiency syndrome (AIDS), with $70 \%$ of the global burden of HIV infection [1]. Widespread coverage of combine antiretroviral therapy (cART) has led to declines in new HIV infection and in the worldwide rates of AIDS-related opportunistic infections [2].

However, some countries are facing the challenge of patient populations that remain undiagnosed and under-served in CART leading to opportunistic infections such as tuberculosis [2]. In 2016, there were 1.4 million new tuberculosis cases among people living with HIV (74\% of whom were living in Africa) and 400,000 deaths [3]. Lymph node tuberculosis is one of the most common forms of extra-pulmonary tuberculosis in these patients [4]. Firm diagnosis requires demonstration of mycobacteria but obtaining a proper specimen may not always be easy.

Furthermore, HIV infection affects the transmission and natural history of hepatitis $\mathrm{C}$ virus (HCV) infection [5]. The transmission efficiency of HCV increases in the presence of HIV infection especially in untreated patients [6]. They are less likely to spontaneously clear HCV infection, have higher HCV viral loads, and experience more rapid $\mathrm{HCV}$ disease progression than those without HIV infection [6]. So, the odds of Hepatitis $C$ virus infection seem to be six times higher in people living with HIV than in HIV-negative [7]. Concerning the interaction between Human immunodeficiency virus (HIV) and sickle cell disease (SCD), little data is available although these affections are endemic and overlapping in this geographic area. SCD has been suggested to reduce the prevalence of HIV infection and disease progression of HIV into AIDS [8] [9]. The objective of this case report was then to highlights the necessity to screen the patient for other co-infections that may alter the prognosis or require long-term treatment in HIV infected patients.

\section{Patient and Case Report}

We report the case of a 35-year-old woman with a past medical history of repeated anaemia and family history of sickle cell disease (two of her cousins). She has had HIV for the past 10 years and refused medication in denial of the disease. She presented with fatigue and weight loss associated to pain in the right flank present four months prior to consultation.

On clinical examination: she was conscious and well oriented with a temperature of $37.7^{\circ} \mathrm{C}$, with hepatomegaly (normal consistency) and icterus, dark colored urine. Moreover, she presented with constitutional symptoms: evening fever, (Figure 1), weight loss (15\% in 4 months), anorexia, fatigue, night sweating. Her body mass index was $16.4 \mathrm{Kg} / \mathrm{m}^{2}$. We found some small, non-tender cervical lymph nodes in the posterior cervical triangle.

Serology was positive for HIV (ELISA) with $451 \mathrm{CD} 4$ cells/mL and HCV antibodies (ELISA) with a viral load of $2613 \mathrm{UI} / \mathrm{mL}$. We found elevated liver enzymes 87.5 UI/L for aspartate amino-transferase (AST) and 130.7 UI/L for alanine amino-transferase (ALT), and elevated bilirubinemia with a total bilirubi- 
nemia of $374 \mathrm{mg} / \mathrm{L}$ and a conjugated bilirubinemia of $320 \mathrm{mg} / \mathrm{L}$. Lactate dehydrogenase (LDH) was mildly elevated with a value of $1295 \mathrm{UI} / \mathrm{L}$; a week later, a control test revealed a value of 911.8 . Inflammatory markers were elevated with a C-reactive protein of $192 \mathrm{mg} / \mathrm{L}$ and an erythrocyte sedimentation rate of 127 $\mathrm{mm}$ in the first hour. Complete blood count showed a normocytic normochromic anaemia of $7.4 \mathrm{~g} / \mathrm{dl}$ of haemoglobin. Haemoglobin electrophoresis was in favour of homozygous (SS) SCD (Haemoglobin S: 81.8\%; Haemoglobin F: 15.3\% (Figure 2).

Abdominal ultrasound showed homogeneous hepatomegaly with multiple celiac lymphadenopathies with an iso-echoic centre and hyper-echoic borders and the largest measuring $26.4 \mathrm{~mm}$ in diameter (Figure 3 ). A chest $\mathrm{x}$-ray shows there was no sign of pulmonary tuberculosis nor other abnormalities.

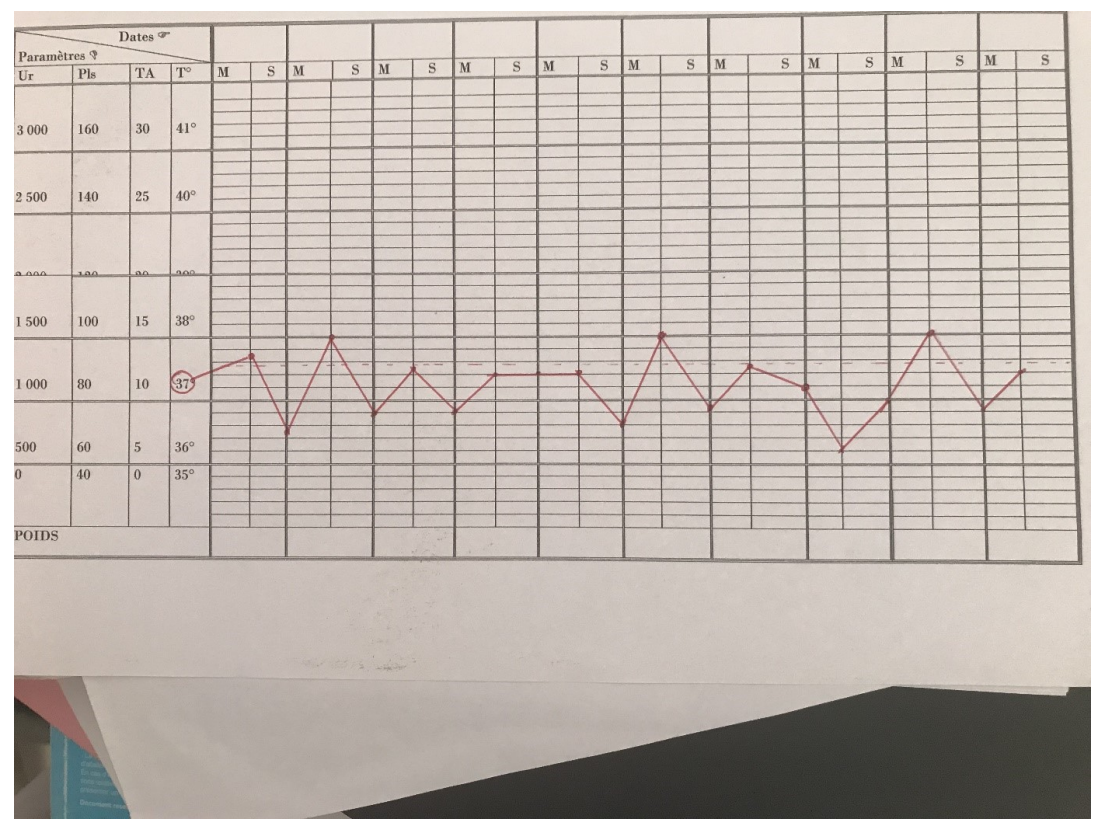

Figure 1. Temperature curve.

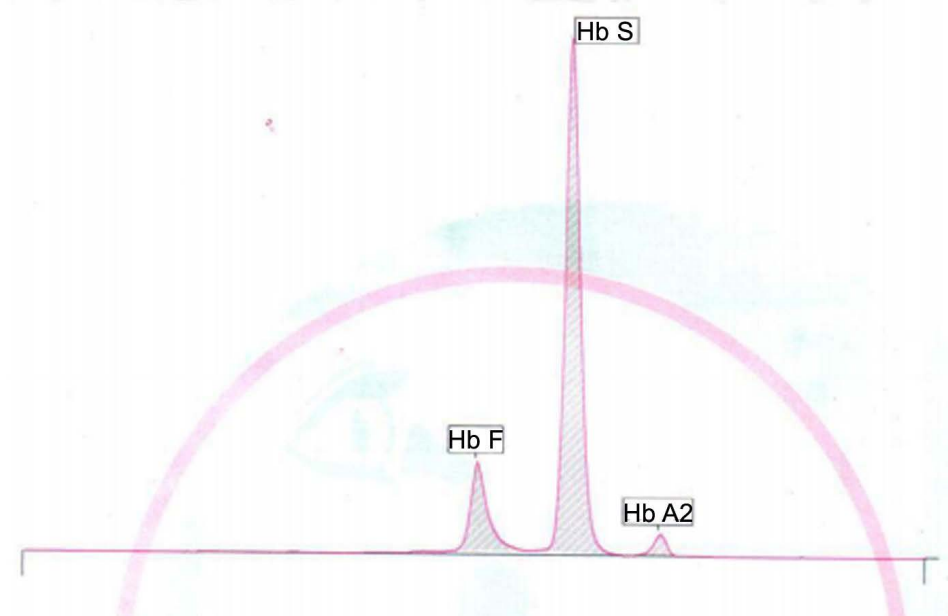

Figure 2. Haemoglobin electrophoresis. 


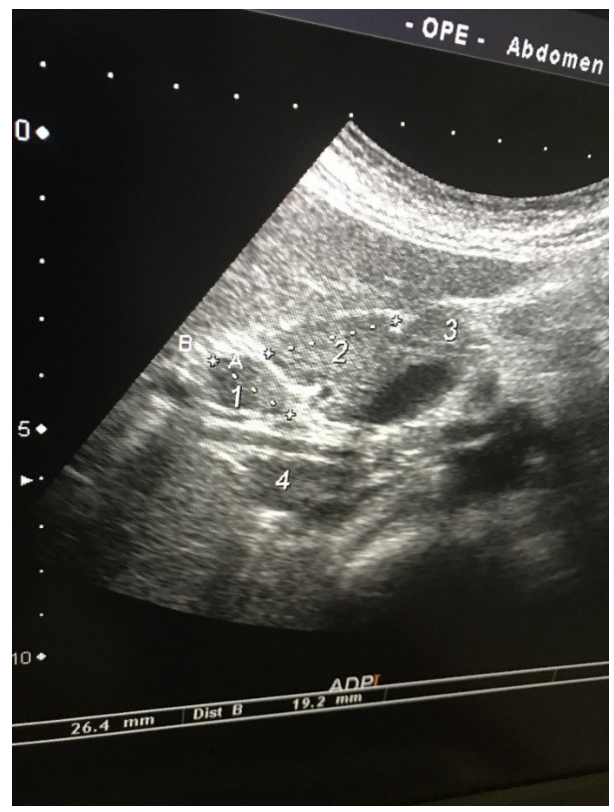

Figure 3. Abdominal lymphadenopathy.

The diagnosis of lymph node tuberculosis was retained on the basis of clinical signs (night fever and sweating, fatigue, anorexia and weight loss of $15 \%$ in 4 months); aorto-mesenteric lymphadenopathy in the abdominal ultrasound; elevated inflammatory markers; in an untreated patient living with HIV since 10 years.

The patient initially received a combined anti-tuberculosis therapy made up of: Rifampicin, Isoniazid, Pyrazinamide and Ethambutol for 2 months. After 2 months, Pyrazinamide and Ethambutol were stopped and Rifampicin and Isoniazid were continued for 4 more months. We prevented Isoniazide neurotoxicity by administering vitamin B6 and supplement vitamin B9 for the correction of anaemia. cART was started 2 weeks later using Tenofovir, Lamivudine and Effavirenz. We delayed the introduction of cART to prevent the immune reconstitution inflammatory syndrome (IRIS). Antiviral therapy for hepatitis $\mathrm{C}$ virus was delayed to the end of anti-tuberculosis drugs to avoid hepatotoxicity and drugs interactions.

After 6 months of anti-tuberculosis treatment, the patient was declared healed. Clinically, there was no longer sign of active tuberculosis (fever, night sweat, anorexia) and the patient gained $13 \mathrm{Kg}(29.5 \%)$. HIV viral load was undetectable. There was decrease in liver enzymes $74 \mathrm{UI} / \mathrm{L}$ for AST and $29 \mathrm{UI} / \mathrm{L}$ for ALT. Prothrombin level was normal (78.8\%). Her haemoglobin level was at 7.7 $\mathrm{g} / \mathrm{dl}$. The patient was then transferred toward a hepato-gastro-enterology unit for pre-therapeutic assessment and treatment of hepatitis $\mathrm{C}$ virus.

\section{Discussion}

We report a case of an unexpected association of HIV, hepatitis C virus infection, lymph node tuberculosis, and sickle cell disease in a 35-year-old woman 
from Cameroon. We didn't find a similar case of this association of these 4 serious life-threatening conditions.

HIV infection is a public health issue in sub-Saharan Africa with around 1.2 million new infections in 2016 [1]. It favours opportunistic infections like tuberculosis and modifies the transmission and natural history of other viral infection like hepatitis C [3] [4] [7].

The patient's refusal to start ART ten years ago at diagnosis of her HIV infection favoured the occurrence of this opportunistic infection. She denied the condition all these years. This raises awareness on the psychosocial follow-up from the announcement of the condition.

Lymph node tuberculosis is one of the most common forms of extrapulmonary tuberculosis in patients living with HIV [4]. Diagnosis requires identification of mycobacteria. Nowadays, various analyses are possible such as: staining for acid-fast bacilli, culture in specific milieu (Lowenstein-Jensen), molecular biology and flow cytometry. In the case of abdominal lymphadenopathy, obtaining a specimen in order to confirm the diagnostic is a challenge in resource limited countries as Cameroon where digestive endoscopy is embryonic and the necessary devices and trained staff limited to a few centres in the country. In this context diagnosis of deep lymph node tuberculosis is essentially clinical-it is based on suggestive clinical and radiological signs in a patient with an immunosuppression (HIV, cancer, etc.)

SCD has been suggested to reduce disease progression of HIV into AIDS. Several hypotheses have been postulated to explain this phenomenon, such as an enhanced immune defence in SCD [8] [9]. This may be because of the up regulation of inflammation, iron metabolism, and immunologic changes in SCD that are not favourable for HIV viral replication [9]. Other authors made the hypothesis that the absence of a functional spleen, which is a major site for HIV invasion and replication, and which is characteristic of SCD patients, is a reason for decreased virulence [10]. This could explain the slow progression of the HIV infection in our patient. After ten years without any treatment, she developed her first opportunistic disease and her $\mathrm{CD}_{4}$ count was not as low as expected (451 cells/mL). Bagasra and colleagues reported in a study that a significant proportion of HIV1-seropositive SS patients may be asymptomatic long-term non-progressors [10]. In these patients, the CD4 T-lymphocyte counts remained high and their viral burdens were remarkably lower than in non-SS HIV1-seropositive [10].

In our case report, hepatitis $\mathrm{C}$ virus and sickle cell disease worsened the prognosis of tuberculosis and HIV disease by increasing the risk of hepatic failure and anti-tuberculosis-medication and ART induced anaemia. However, there was a favourable evolution after 6 months of treatment. The patient was declared healed after 6 months of anti-tuberculosis drugs and her HIV viral load was undetectable.

\section{Conclusion}

In conclusion, the diagnostic of lymph node tuberculosis is not always easy in 
resources limited countries where obtaining a proper specimen for laboratory analysis is a challenge. Diagnostic in such condition is essentially based on the clinical sign. It is important to screen patient for other co-infections that may alter the prognosis or require long-term treatment.

\section{Ethical Statement}

The patient gave inform consent for this case to be published.

\section{Consent for Publication}

Written informed consent for publication of their clinical details and/or clinical images was obtained from the patient.

\section{Authors' Contribution}

HD: conception and design, data collection, manuscript drafting, and critical revision of manuscript. GTT: data collection and critical revision of manuscript. VAN: manuscript drafting and critical revision of manuscript. SL: data collection and critical revision of manuscript. RSD: data collection and critical revision of manuscript. LNM: data collection and critical revision of manuscript. BHMN: data collection, manuscript drafting, and critical revision of manuscript.

All authors have read and approve the final version of the manuscript.

\section{Acknowledgements}

We thank the patient who gave her consent to publish the case report.

\section{Conflicts of Interest}

The authors declare no conflicts of interest regarding the publication of this paper.

\section{References}

[1] UNAIDS DATA 2017. https://www.unaids.org/en/resources/documents/2017/2017_data_book

[2] Tanser, F., Bärnighausen, T., Grapsa, E., Zaidi, J. and Newell, M.-L. (2013) High Coverage of ART Associated with Decline in Risk of HIV Acquisition in Rural KwaZulu-Natal, South Africa. Science, 339, 966-771. https://doi.org/10.1126/science.1228160

[3] WHO (2018) Tuberculosis. https://www.who.int/mediacentre/factsheets/fs104/en/

[4] Namme, L.H., Doualla, M.S., Bertrand, M.N.H., Elvis, T., Achu, J.H. and Christopher, K. (2013) Extrapulmonary Tuberculosis and HIV Coinfection in Patients Treated for Tuberculosis at the Douala General Hospital in Cameroon. Annals of Tropical Medicine and Public Health, 6, 100-104. https://doi.org/10.4103/1755-6783.115207

[5] Deng, L.-P., Gui, X.-E., Zhang, Y.-X., Gao, S.-C. and Yang, R.-R. (2009) Impact of Human Immunodeficiency Virus Infection on the Course of Hepatitis C Virus Infection: A Meta-Analysis. World Journal of Gastroenterology, 15, 996-1003. https://www.ncbi.nlm.nih.gov/pmc/articles/PMC2653408/ 
https://doi.org/10.3748/wjg.15.996

[6] Thomas, D.L., Astemborski, J., Rai, R.M., Anania, F.A., Schaeffer, M., Galai, N., et al. (2000) The Natural History of Hepatitis C Virus Infection: Host, Viral, and Environmental Factors. The Journal of the American Medical Association, 284, 450-456. https://doi.org/10.1001/jama.284.4.450

[7] Platt, L., Easterbrook, P., Gower, E., McDonald, B., Sabin, K., McGowan, C., et al. (2016) Prevalence and Burden of HCV co-Infection in People Living with HIV: A Global Systematic Review and Meta-Analysis. The Lancet Infectious Diseases, 16, 797-808. http://linkinghub.elsevier.csom/retrieve/pii/S1473309915004855 https://doi.org/10.1016/S1473-3099(15)00485-5

[8] Owusu, E.D.A., Visser, B.J., Nagel, I.M., Mens, P.F., Grobusch, M.P. and Mayer K.H. (2015) The Interaction Between Sickle Cell Disease and HIV Infection: A Systematic Review. Clinical Infectious Diseases, 60, 612-626.

https://doi.org/10.1093/cid/ciu832

[9] Obaro, S. (2012) Does Sickle Cell Disease Protect against HIV/AIDS? Sexually Transmitted Infections, 88, 533. https://doi.org/10.1136/sextrans-2012-050613

[10] Bagasra, O., Steiner, R.M., Ballas, S.K., Castro, O., Dornadula, G., Embury, S., et al. (1998) Viral Burden and Disease Progression in HIV-1-Infected Patients with Sickle Cell Anemia. American Journal of Hematology, 59, 199-207. https://doi.org/10.1002/(SICI)1096-8652(199811)59:3<199::AID-AJH4>3.3.CO;2-C

\section{List of Abbreviations}

AIDS: acquired immunodeficiency syndrome;

HIV: Human immunodeficiency virus;

cART: combined antiretroviral treatment;

SCD: sickle cell disease;

AST: Aspartate amino-transferase;

ALT: alanine amino-transferase. 